\title{
LA ENCRUCIJADA DE LA DOBLE MEMORIA EN PLOTINO Y EN EL PLATONISMO TARDOANTIGUO José Molina Ayala*
}

DOUBLE MEMORY CROSSROADS IN PlotinUS AND LATE PlatonISM

RESUMEN: El tema de la memoria es infinito. En este texto el autor se ocupa de la memoria, facultad del alma que recuerda, en el platonismo tardoantiguo, específicamente en Plotino ("Sobre los problemas del alma"). El tema no es sencillo, pero este acercamiento permite ordenar las conpeciones antiguas de la memoria, así como situarlas en su contexto temporal en la tradición de la Antigüedad.

Palabras Clave: memoria, Plotino, Jámblico, platonismo tardío, alma.
ABSTRACT: The topic of memory is infinite. The author reflects on memory, that faculty of the soul that remembers from the perspective of late Platonism, particularly that of Plotinus ("Problems with the soul"). This topic is challenging but by doing so we can classify the old notions of memory and give them their appropriate place in the Antiquity tradition.

KEYwORDS: memory, Plotinus, Iamblichus, Platonism, late, soul.
RECEPCIÓN: 11 de diciembre de 2014.

ACEPTACIÓN: 14 de enero de 2015.
* Centro de Estudios Clásicos, Instituto de Investigaciones Filológicas, UNAM. 


\author{
LA ENCRUCIJADA \\ DE LA DOBLE MEMORIA EN \\ PLOTINO Y EN EL \\ PLATONISMO TARDOANTIGUO
}

$\mathrm{E}_{1}$ en esta nota sólo me ocuparé del platonismo de la Antigüedad tardía, más específicamente de Plotino, sobre quien debo hacer algunas consideraciones previas que me parecen pertinentes.

Plotino nació y vivió en el siglo tercero después de Cristo; de modo que ya existen entre él y Platón más de cinco siglos. Esta diferencia suele soslayarse, porque se compara el pensamiento plotiniano con sus fuentes fundamentales, y ocurre que la búsqueda y crítica de sus fuentes deja a Plotino y demás platónicos de la Antigüedad tardía como meros o malos repetidores de las doctrinas aristotélicas y platónicas, y a nosotros nos deja como quien pela una cebolla, llorando y sin nada. Este enfoque es, digámoslo de una vez, errado; dicho de otra manera, no se puede hacer la valoración de Plotino y de otros de sus contemporáneos usando como criterio único su adhesión o separación con respecto al pensamiento de Platón o de Aristóteles; hay que aprender a juzgarlos en sus propios términos, sin dejar por eso de hacer las precisiones necesarias respecto de sus fuentes. Más allá de soslayar los aportes originales de los platónicos tardoantiguos, se ha llegado incluso a suponer, con perniciosas consecuencias, que alguna de sus interpretaciones es en realidad algo presente en Platón mismo, lo cual es más grave tratándose de un asunto tan importante como la postulación de la existencia de dos 
mundos distintos: éste en que vivimos y otro de las ideas; por eso, Gadamer, ya en 1996, encuentra necesario señalar que "la belleza, la justicia, el bien no son en ningún momento un segundo mundo de esencias. Este último es una ontologización errónea de las intenciones de Platón, originada por el influjo de la tradición posterior". Ese supuesto segundo mundo, continúa Gadamer, "se perfila ya en la crítica de Aristóteles, quien, por su parte, se guiaba por su interés en la física. Es el neoplatonismo -así llamamos hoy a esa tradición- el primero que convierte a Platón en un pensador de la trascendencia". ${ }^{1}$ De modo que, para la recta lectura de lo que de verdad dijo Platón y para la justa valoración de los platónicos tardoantiguos, hay que hacer un deslinde puntual que no traslape o proyecte la doctrina de éstos en aquél ni viceversa.

Plotino ya es, digámoslo así, uno de nosotros, alguien que va al pasado de la Grecia clásica a buscar soluciones para su propio tiempo, y en ese sentido nos debe inspirar porque hemos de decir que él no fracasó en su empresa, sino que con gran originalidad, por estar sustentada sobre la exégesis y el comentario de los textos antiguos, tomando muy en serio y vitalmente su platonismo, supo ser libre y poderoso para exponer su propio

${ }^{1}$ H. G. Gadamer, El inicio de la filosofia occidental, 1999, Barcelona, Paidós (Paidós Studio, 112), p. 66. pensamiento en escritos altamente condensados e intrincados. Para aproximarse a los tratados plotinianos, que son fabulosas y prodigiosas síntesis de los autores antiguos en general y de Platón en particular, no basta desenredar la madeja de las fuentes.

Otro factor que perturba el juicio sobre Plotino es el desconocimiento que suele tenerse de sus contemporáneos; pocas veces se percibe que el debate, más que con Aristóteles o con Platón, es con personajes más cercanos a su tiempo, con Alejandro de Afrodisia o con Porfirio o con los gnósticos o con otros. Afortunadamente, la filología últimamente nos ha puesto en las manos las fuentes de los autores de la Antigüedad tardía, aunque aquí en México todavía nos queda mucho por leer y estudiar.

Así advertidos, diré que el tema de la memoria en Plotino está tratado principalmente en medio de una exposición Sobre los problemas del alma, que ocupa los tratados del tres al cinco de la cuarta Enéada, ${ }^{2}$ se trata de un exposición sobre temas importantes vinculados con la manera en que el alma se relaciona con el cuerpo, de los cuales Plotino se ocupó aguijoneado ya por la presencia de Porfirio, y hay que saber que, como dice Riccardo Chiaradonna, "el tratamiento de Plotino del tema de la memoria es posi-

${ }^{2}$ En otras partes de las Enéadas hay pasajes pertinentes, pero básicamente la doctrina sobre la memoria está en estos tratados. 
blemente la sección más desconcertante y difícil de las Enéadas". ${ }^{3}$

El asunto no es transparente para quien se acerca por primera vez al platonismo tardoantiguo: hay que distinguir entre distintos tipos de alma; entre el Alma, entendida como hipóstasis (la cual se originó a partir del Intelecto, que a su vez se originó a partir del Uno), y el Alma del mundo y el alma individual, que es, ante todo y de acuerdo con los principios ortodoxos del platonismo, una entidad no corpórea. ${ }^{4}$ Por otro lado, como una consideración pertinente pero anterior, Plotino deja claro que, a diferencia del alma, el intelecto no tiene memoria, pues sus objetos le están presentes en todo momento y no la necesita; tampoco necesitan memoria los cuerpos celestes que están animados; de manera que el tema de la memoria es, preponderantemente, un tema antropológico en que se entrecruzan muchos asuntos de diversa índole: ontológica, cosmológica, psicológica, etcétera.

La memoria es una facultad que sólo pertenece al alma individual mientras está en el cuerpo, pues mientras está en el mundo inteligible, como

${ }^{3}$ R. Chiaradonna, "Plotinus on Memory, Recollection and Discursive Thought", en L. Castagnoli y P. Ceccarelli (eds.), Greek Memories: Theories and Practices, Cambridge, Cambridge University Press, en prensa.

${ }^{4}$ Véase el capítulo III, "El alma, el mundo y el hombre en la enseñanza de Plotino", en F. García Bazán, Plotino y la mística de las tres hipóstasis, 2011, Buenos Aires, El Hilo de Ariadna, pp. 237-97. señalamos, no la necesita. Porfirio, por ejemplo, para mostrar la virtud superior de su maestro, en su Vida de Plotino, ${ }^{5}$ describe cómo no le era necesario revisar dónde se había quedado, si había sido interrumpido mientras escribía; sucede como si, por ejemplo, un enamorado le dijera a su amada, "no te recuerdo pues no te olvido"; eso sería una imagen de la vida del alma que vive en el intelecto. El asunto se volverá importante; no hay que olvidar que, según Plotino, el alma humana no desciende del todo cuando entra en el cuerpo, sino que hay un alma o una parte del alma que no desciende y que está permanentemente en contacto con la vida del intelecto, no sujeta a las vicisitudes de la realidad temporal y conociendo las realidades eternas y permanentes.

Plotino comienza con una pregunta importante, ¿qué o quién es lo que recuerda? Y su respuesta es el alma. Podría parecer obvio, pero le es importante separarse de la visión física o mecanicista de la memoria como mero archivo de las impresiones. Tal como Platón estableció en el Teeteto, es el alma la que percibe, la que conoce, y no el ojo ni la mano; también Plotino establece como principio de una facultad, tal como la memoria, no la descripción física de

${ }^{5}$ Porfirio, Vida de Plotino, 8 (Plotin, Ennéades, 1924, Paris, Société d'Édition «Les Belles Lettres», trad. Émile Bréhier). 
un fenómeno, sino un sujeto que ejerce dicha facultad. Esa facultad, la memoria, se confunde con otra, que es la imaginación. De hecho, la imaginación sola ya es cierta memoria, porque puede hacer presente lo que está ausente; el énfasis de la caracterización de la memoria, en contraste con la imaginación, está puesto en que la memoria retiene la imagen; en efecto, Jámblico, en su tratado Acerca del alma, define la memoria como "retención de la imagen" (he mneme katojé ousa phantásmatos), ${ }^{6}$ puesto que se hace énfasis en que el alma, mediante esta facultad, retiene y evita que se pierda la imagen formada por la imaginación. Se sabe ahora que la palabra katojé no formaba parte del vocabulario de los escritos no espurios de Aristóteles: se la encuentra en Porfirio, en Jámblico y en un epítome del tratado Sobre la Memoria de Aristóteles. Se trata, pues, de una reelaboración léxica de lo que Aristóteles llamaba una hexis, una posesión.

Cabe hacer notar que la precisión mediante la cual se caracteriza a la memoria como retención es importante porque, de esta manera, se evita una visión meramente física de la memoria, que pondrá énfasis en la fuerza con que lo sensible se imprime en el

${ }^{6}$ Jámblico, Acerca del alma, 14 (Iamblichus, De Anima, 2002, Leiden, Brill, edición de F. Finamore y John M. Dillon). alma; para explicar esta visión, digamos mecanicista de la memoria, suele recurrirse a una imagen usada por Platón en el Teeteto, que es la de la cera en que se graban las impresiones; la memoria, pues, sería como una inscripción que permanece en la tablilla, dependiendo de la fuerza con que se hizo y de la cualidad de la cera. Pero, ¿cómo se "graban" los recuerdos en la mente? Aristóteles, en el inicio de la Metafisica, sostiene que una experiencia fundamental para el arte y la ciencia se configura por la multitud de recuerdos del mismo asunto $;{ }^{7}$ no es gratuito que, cuando en la escuela queríamos aprender algo de memoria, solíamos repetirlo infinitas veces; allí mismo, Aristóteles señala que los animales que tienen memoria son más inteligentes, pero eso no significa que memoria e inteligencia se confundan; añade que aprenden quienes tienen oído. Es curioso que la memoria suele asociarse con el campo de lo visual, o con los sueños, lo cual ocurre por su vinculación con la imaginación; pero esta asociación de la memoria con el oído para el aprendizaje se precisa más en el tratado aristotélico Sobre la memoria, ${ }^{8}$ que sin duda Plotino tomó

${ }^{7}$ Aristóteles, Metafísica, 980 b 29-981 a 1.

${ }^{8}$ Aristotle on Memory and Recollection, 2007, Leiden/ Boston, Brill, Text, Translation, Interpretation, and Reception in Western Scholasticism by David Bloch. 
en cuenta; ${ }^{9}$ la memoria se asocia, como los sonidos, no con la luz, en cuyo caso la relación sería espacial, sino con el tiempo; es decir, la memoria tiene relación necesaria con el pasado y el tiempo hace que las impresiones de lo sensible se desdibujen, pero la memoria es la facultad que las fija y las retiene.

La palabra mneme, que suele referir el recuerdo no como objeto sino como proceso psicológico, no está como entrada en el Diccionario Etimológico de Chantraine, ${ }^{10}$ pero sí está mimnesko, el verbo recordar, cuyo infijo-sk-expresa la realización de un proceso repetido; se relaciona, curiosamente no con meno, que significa "permanecer", "mantenerse firme", "estar", "quedarse", sino con memona, con menos y con mainomai. Es un poco sorprendente, o al menos así me lo parece: memona es un perfecto con valor de presente, que,

${ }^{9}$ Sobre la relación entre Aristóteles y Plotino respecto del tema de la memoria puede verse: Henry J. Blumenthal, "Plotinus' Adaptation of Aristotle's Psychology, Sensation, Imagination and Memory", en R. Baine Harris (ed.), The Significance of Neoplatonism, 1976, Norfolk (VI), International Society for Neoplatonic Studies, Old Dominion University. Véase también Angela Longo, "Memoria inattiva e memoria attiva in Plotino ("Enneadi" I 2, 4): un confronto con Aristotele ("De Anima" II 5 e III 4)", en Testis Fidelis. Studi di filosofia e scienze umane in onore di Umberto Galeazzi, 2012, Napoli, Orthotes Editrice, a cura di Domenico Bosco, Francesco Paolo Ciglia, Luigi Gentile, Loreta Risio, pp. 425-41.

${ }^{10}$ Pierre Chantraine, Dictionnaire étymologique de la langue grecque: Histoire des mots, 1980, Paris, Klincksieck. según el Diccionario Liddell-Scott, ${ }^{11}$ tiene como cognados precisamente a menos y a mainomai, y significa: "desear ardientemente", "estar ansioso de", "aspirar a", "buscar", "tratar de"; "proponerse", "resolverse o determinarse a"; "lanzarse apresurada o violentamente". En este sentido, el arte de la memoria aparece en Plotino como el arte de la atención, y el arte de la atención es el arte del interés. Uno recordaría mejor aquello de lo que uno está ansioso, aquello a lo que uno se lanza con violencia, esto es, a lo que uno está intencionalmente dirigido, digamos, en términos de Husserl.

Por otra parte, la siguiente palabra relacionada con mimnesko, menos, es muy interesante. Menos significa "fuerza", "vigor", "ímpetu”, "poder", "fuerza vital", "vida", "alma", "sangre", "furia", "rabia", "cólera", "intención", "propósito" "temple", "talante", "temperamento". Significativamente, aparece a veces en Homero, en endíadis junto con thymós, que es también "el ánimo", "el furor", "la cólera". Es de notar que Plotino se refiere a la memoria no sólo como una facultad, una dynamis, sino también con isjys, como "fuerza" del alma que retiene la imagen; esa retención es una actividad del alma y no un suceso en que el alma permanezca pasiva.

${ }^{11}$ Henry George Liddell and Robert Scott, $A$ Greek-English Lexicon, 1968, Oxford, Oxford Clarendon Press, 9a. ed., s. v. mémona. 
En la tradición platónica del Fedro, la palabra con la que anamimneskomai tiene mayores resonancias es mainomai, "poner furioso o rabioso", "rabiar", "estar loco", "alocado", "transportado", "fuera de sí", "estar poseído", "estar cegado", "mostrarse simple e indiscreto", "moverse o lanzarse con furia"; el verbo tiene que ver con manía. Platón en el diálogo citado se refiere a cuatro manías por las cuales el alma recupera las alas que perdió al encarnarse en un cuerpo: ${ }^{12}$ la manía del enamoramiento, que fácilmente puede uno relacionar con el Banquete, la vía ascendente de la belleza por la cual el alma enamorada recuerda lo percibido antes de encarnarse; como en su Piedra de Sol recuerda platónicamente Octavio Paz, que cuando dos se besan "brotan las alas en las espaldas del esclavo", el alma recuerda que antes estaba alada y el amor le ayudaría a recuperar sus alas. Platón también le reserva un lugar a la manía propia de la poesía, de modo que también el poeta recuerda su origen celeste. Es el poeta quien, con sus obras, trae al mundo una prueba de la existencia de un ámbito superior al meramente sensible; Hesíodo, por ejemplo, en su Teogonía da a conocer el canto que recitan las deidades cuando se reúnen; el poeta tuvo acceso a lo que pasa en la dimensión celeste. Como decía Hölderlin, "todo lo que permanece lo fundan los poetas", y lo que permanece, porque pertenece al ámbito celeste de lo eterno, es lo que se recuerda gracias a las facultades poéticas.

Otra manía, es decir, otra forma del recuerdo, otra manera en que el alma percibe que los datos de lo sensible no son lo único o lo definitivo, es la del entusiasmo religioso, relevante en el contexto del platonismo tardío, en el caso de la confrontación entre Plotino y Jámblico. Este último había señalado la teúrgia como el medio óptimo y más elevado mediante el cual las almas se unen subsecuentemente a los dioses, al Intelecto y finalmente al Uno. Pero esta unión no podía ser conseguida por los medios meramente intelectuales del ser humano, sino que era concedida por los dioses en los ritos teúrgicos; por el contrario, Plotino y Porfirio decían que son los medios intelectuales propios de la filosofía quienes podían conseguir esta unión; de hecho, la filosofía es precisamente otra manía de las señaladas por Platón en el Fedro.

Plotino, considerando la esencia pura del alma, anula una facultad como la memoria; según Jámblico ${ }^{13}$ la anula por considerarla una facultad irracional que se adhiere al alma sólo cuando está en el cuerpo, pues Plotino considera que sólo el razonamiento puro, sin mezcla de lo sensible, tiende hacia la esencia pura del alma, como si dicho razonamiento, ya libre de las 
perturbaciones de lo corporal, tuviera una facultad connatural respecto a la idea misma de su sustancia. Pero, también según Jámblico, Platón considera a la memoria como algo propio de las almas mismas y de los seres vivos, distinguiéndola de acuerdo con cada vida, o bien, de acuerdo con la vida del alma en sí misma, o bien, con la vida del alma en el ser vivo, en el cuerpo animado. Según Jámblico, para Porfirio y Plotino las almas proyectan sus facultades sobre el universo, se originan o se desarrollan por los requerimientos de la vida contaminada con lo sensible; pero una vez que cesa su vida material, sus facultades también se pierden o se retraen hacia el alma; sin embargo, Jámblico cree que es verosímil, dado que cree que el alma se encarna del todo, que sus facultades, entre ellas la memoria, están y permanecen en el universo y que quizá no se pierden. La memoria es una facultad que está en el alma, pero no es symplerotiké de ella, esto es, ni es capaz de completarla ni forma parte esencial de ella.

Ahora bien, cabe recordar que en el drama que en el pensamiento plotiniano vive el alma como hipóstasis, es decir, como entidad autónoma, generada por el intelecto, ésta se atrevió, tuvo la osadía (tolmé) ${ }^{14}$ de arrojarse hacia la materia; casi como adolescente rebelde que busca individuarse, se olvida de quién es su

\footnotetext{
${ }^{14}$ Plotino, Enéada V, 1 (30), 1
}

padre, del intelecto, y se olvida de sí misma. Este atrevimiento es el que ha hecho que el alma se arroje hacia lo sensible, y arrojándose a lo sensible se entrega entera a lo divisible, se une a la materia y la organiza. Y como el mismo Plotino hace la precisión, los principios de todo, el Uno, el Intelecto y el Alma arquetípica, también se dan proporcionalmente en el ser humano, de modo que también el alma humana ha vivido análogamente ese drama del olvido de sí e igualmente se ha olvidado de sus principios. El trabajo filosófico estribará prácticamente en conseguir que el alma se acuerde de quién es ella, en su más profundo ser, una sustancia incorpórea, y recuerde los vínculos esenciales que la unen con el intelecto, de quien, según Plotino, no llega a separarse nunca del todo. Esta doctrina del alma no descendida del todo es lo que diferencia a Plotino también de los otros filósofos platónicos de la Antigüedad tardía, y de manera importante lo diferencia de Jámblico quien, por un mayor aristotelismo, concibe que el alma desciende por completo a la materia; enseña también que no sin concurso de la materia y, además, con ayuda de los dioses, el alma emprenderá su regreso al ámbito inteligible.

Pero Plotino especifica que la memoria es doble, o bien, que hay dos memorias, dependiendo del objeto hacia el que esta facultad tiende, 
y en esto, aun bajo la perspectiva de Jámblico, es platónico ortodoxo. La memoria puede tender hacia lo sensible; recordamos que es una facultad del alma mientras el alma está en el cuerpo; esta memoria hace presente al alma lo que en determinado momento está ausente, en este caso lo sensible, y en el acto de recordar la facultad simultáneamente se vuelve consciente de sí misma, recuerda y se da cuenta de que recuerda; pero hay otra memoria que está en estado inconsciente, que persigue las realidades inteligibles y que más que una facultad debe concebirse como una disposición (hexis), dado que ésta considera objetos que el alma retiene en sí misma (aquí vuelve el término catojé); en este caso lo ausente, a lo cual esta memoria puede o no llegar a hacer presente, son realidades inteligibles, los objetos de conocimiento que se hallan en el Intelecto; cabe mencionar también que, para Plotino, a diferencia de lo que cree Aristóteles, el alma puede pensar sin imágenes, y en caso de presentarse la memoria superior, la que de manera consciente ya no se dirige a lo sensible, en ella los recuerdos no son imágenes de lo material, sino reflejos de los inteligibles, de las realidades eternas. Mientras que a la memoria sensible la llama mneme, Plotino parece reservar a la memoria superior el nombre de anamnesis. Por otra parte, cuando el alma está en esta memoria superior, en vida o habiendo dejado al cuerpo, el recuerdo de los objetos de la memoria inferior se vuelve superfluo, como si sus objetos cayeran en el olvido, como si sólo quedaran en estado latente.

Consecuentemente, como hay dos memorias, habrá dos olvidos, ${ }^{15}$ y un constante recuerdo de lo sensible provocará el olvido de lo inteligible, y viceversa, la memoria de lo inteligible dejará en la sombra del olvido a lo sensible, como en una especie de quiasmo. Lo interesante es que también para Plotino lo sensible puede ser ambiguo porque, o nos ata a lo sensible, o, de acuerdo con el trabajo del alma, también lo sensible puede ser punto de arranque para el ascenso del alma hacia lo inteligible; el filósofo, por su actividad intelectual, sabrá descubrir los vestigios de lo inteligible en lo sensible y, aunque parezca que hace lo mismo que las demás personas, su vida será más plena porque tendrá cada vez más memoria de sus principios y de sí mismo. ${ }^{16}$

${ }^{15}$ D. P. Taormina, "Plotino. El alma y sus dos olvidos", Revista Latinoamericana de FilosofíaAnejo 2010, pp. 353-84.

${ }^{16}$ Para la elaboración de estas líneas me basé fundamentalmente en los siguientes trabajos, que generosamente Daniela Patrizia Taormina puso en mis manos; son más amplios y detallados, más precisos y profundos, son esenciales y un excelente comienzo para tratar el tema de la memoria en Plotino: D. P. Taormina, "Dalla potenzialità all'attualità. Un'introduzione al problema della memoria in Plotino", en Thomas Bénatouil, Franco Trabattoni, Gerd Van Riel (eds.), Plato, Aristotle or both? 
Dialogues between Platonism and Aristotelism in Antiquity, 2010, Hildesheim, Olms, pp. 139-59; id., "Plotino. El alma y sus dos olvidos", Revista Latinoamericana de Filosofía-Anejo 2010, pp. 353-84. Riccardo Chiaradonna, "Plotinus on Memory, Recollection and Discursive Thought", en L. Castagnoli y P. Ceccarelli (eds.), Greek Memories: Theories and Practices, Cambridge, Cambridge University Press, en prensa. También son muy útiles y luminosos, aunque de modo colateral a lo aquí expuesto: D. P. Taormina, "Coloro che guardano e provano un turbamento. Memoria degli intelligibili e percorso anagogico secondo Plotino, trattato 33
[II 9] 16", M. Marsola, L. Ferroni (eds.), Estratégias anti-gnósticas nos escritos de Plotino, San Paolo, Rosari \& Paulus (en prensa), prefazione J.-M. Narbonne; R. Chiaradonna, "Plotinus' Account of Cognitive Powers of the Soul: Sense Perception and Discursive Thought", en Topoi 31 (2), pp. 191201; Angela Longo, "Memoria inattiva e memoria attiva in Plotino ("Enneadi" I 2, 4): un confronto con Aristotele ("De Anima" II 5 e III 4)", en Testis Fidelis. Studi di filosofia e scienze umane in onore di Umberto Galeazzi, 2012, Napoli, Orthotes Editrice, a cura di Domenico Bosco, Francesco Paolo Ciglia, Luigi Gentile, Loreta Risio, pp. 425-41. 